\title{
APROXIMACIÓN A LA DESIGUALDAD ECONÓMICA A TRAVÉS DE FUENTES FISCALES BAJOMEDIEVALES: VALLS (1378), SEVILLA (1384) Y PALMA (1478) ${ }^{1}$
}

\author{
Approaching Economic Inequality through Late Medieval Tax \\ Records: Valls (1378), Sevile (1384) and Palma (1478)
}

\author{
Luis Almenar Fernández \\ luisal5@uv.es \\ Universitat de València. España \\ Guillermo Chismol Muñoz-Caravaca \\ guillermo.chismol@uv.es \\ Universitat de València. España \\ Lledó Ruiz Domingo \\ lledo.ruiz@uv.es \\ Universitat de València. España \\ Fecha de recepción: 03/06/2017 \\ Fecha de aceptación: 21/09/2017
}

RESUMEN: El interés por la desigualdad en la riqueza entre las sociedades preindustriales se ha reavivado con fuerza en la historia económica. Los historiadores consagrados al período bajomedieval, y más concretamente de la Península ibérica, tienen por delante el reto de ponerse a la altura de sus compañeros modernistas. Algo posible gracias a la existencia de métodos de análisis ya desarrollados en la disciplina económica, y de fuentes fiscales basadas en una estimación del patrimonio de los contribuyentes. Con el fin de aproximar el tema, este trabajo analiza tres casos concretos, procedentes

${ }^{1}$ Universitat de València. Este trabajo forma parte del proyecto «Crecimiento económico y desigualdad social en la Europa mediterránea, siglos XIII-XV» (HAR2014-58730-P). Esta investigación cuenta con el apoyo de una ayuda de Formación del Profesorado Universitario (FPU), una ayuda de Formación del Personal Investigador (FPI) del Ministerio de Educación, Cultura y Deporte del Gobierno de España y, finalmente, de una ayuda predoctoral Atracció de Talent de la Universitat de València. 
de diversas poblaciones peninsulares bajomedievales: Valls (1378), Sevilla (1384) y Palma (1478). En el caso de Valls y Sevilla, se ha recurrido a transcripciones o material ya publicado, mientras que para el caso de Palma se ha estudiado un registro original inédito. La primera parte plantea los límites y posibilidades del uso de estas fuentes para el estudio de la desigualdad en el contexto bajomedieval. La segunda explica los fundamentos de nuestra metodología, basada en el cálculo de coeficientes de Gini y el análisis de la distribución de la riqueza por deciles, aplicada a esta fuente concreta. La tercera y última parte muestra algunos resultados provisionales, fundamentalmente, desde la perspectiva de las desigualdades entre grupos sociales, entre poblaciones rurales y urbanas y, finalmente, entre hombres y mujeres.

Palabras clave: desigualdad económica; fuentes fiscales; Iberia; Baja Edad Media.

ABSTRACT: Wealth inequality in pre-industrial societies is a newly reinvigorated topic in economic history. Late medieval historians, particularly those of Iberia, face the challenge to catch up with their early modern counterparts. This proves completely possible due to the existence of analytic methods already developed in economics, as well as tax sources based on patrimony estimates of tax-payers. With the aim of addressing such a topic, this essay analyses three cases coming from various late medieval Iberian populations: Valls (1378), Seville (1384) and Palma (1478). In the case of Valls and Sevile the evidence has been based on transcriptions of available material, while for Palma we have studied a original unpublised record. Part one poses the limits and possibilities of the usage of these sources for the study of inequality in the late medieval context. Part two explains the foundations of our methodology, which relies on the calculation of Gini coefficients and deciles-based wealth distribution, as applied to these sources. Finally, part three shows provisional evidence from the viewpoint of inequality between occupational groups, rural and urban populations and, in the end, men and women.

Keywords: economic inequality; tax sources; Iberia; Later Middle Ages.

SUMARIO: 1. Introducción. 2. Las fuentes para el estudio de la desigualdad en la riqueza durante el período bajomedieval. 3. Nuestra propuesta metodológica. 4. Estudio de casos: algunos resultados provisionales. 5. Conclusiones. 6. Bibliografía.

\section{INTRODUCCIÓN}

La desigualdad crece en Europa. Es el rostro más rotundo de una crisis que, con casi diez años de duración, ha dejado de ser una realidad solamente financiera o económica. El aumento de las diferencias entre los miembros de una sociedad es la dimensión más cotidiana de la crisis, un fenómeno que ha reavivado el interés por el estudio de la desigualdad en la riqueza. Naturalmente, no existen -ni han existido nunca- sociedades completamente igualitarias: siempre ha habido ricos y pobres. La pregunta es qué niveles de desigualdad son aceptables y, por el contrario, cuáles perniciosos. Porque como se han esforzado en demostrar diversos autores, tasas muy elevadas de desigualdad dividen a los miembros de una sociedad: tienen un impacto rotundo en la movilidad social, pero también en la esperanza de vida e, incluso, en la mortalidad, la salud mental, y la tasa de homicidios (Wilkinson, 2016; Göran, 2015). Y así, el estudio de la desigualdad ha experimentado un fuerte 
impulso desde los últimos años por parte de los historiadores económicos y de los propios economistas. También está captando cada vez más la atención de los historiadores consagrados a la economía preindustrial, medievalistas y modernistas, en la búsqueda de las dimensiones alcanzadas por la desigualdad antes de la industrialización, y de su relación con los procesos de crecimiento o depresión económica.

Evidentemente, ni la desigualdad ni su vinculación con los cambios en la economía son temas nuevos, sino que han sido explorados desde hace mucho tiempo, prácticamente, desde el nacimiento de la disciplina económica. En toda esa tradición de trabajo, los estudiosos del tema se han posicionado generalmente en dos grandes visiones sobre la relación entre desigualdad y crecimiento económico. La primera de ellas tiene su base en los estudios del economista rusoestadounidense Simon Kuznets. En su trabajo sobre la distribución del ingreso en los EE. UU. en la primera mitad del siglo XX, Kuznets pudo establecer una relación positiva entre el crecimiento de la economía y el descenso de las desigualdades sociales. Según sus observaciones, el aumento de la renta per cápita que habría seguido a las primeras fases de la industrialización americana (a finales del siglo XIX) habría crecido pareja a un aumento de la desigualdad en el ingreso. No obstante, a medida que la economía industrializada avanzaba, la desigualdad no solo se habría estancado, sino que finalmente habría descendido (este efecto de "U» invertida es la famosa "curva de Kuznets»). La explicación es que, con el despegue de una economía industrializada, pocos miembros del espectro social pasan al sector secundario y terciario. Ahora bien, a medida que esos sectores cobran un peso más estructural y se estabilizan, más personas desarrollan este tipo de ocupaciones, con un nivel de renta más elevado, lo que reduce la distancia en la riqueza dentro del espectro social (Kuznets, 1955).

La visión kuznetsiana es, en definitiva, que el crecimiento económico reduce la desigualdad. El aumento de esta es, en principio, un subproducto pasajero de las primeras fases de la industrialización. En una economía ya en un estadio de desarrollo maduro, las desigualdades en la riqueza se reducirían a medida que más personas aumentan sus ingresos con las nuevas oportunidades que ofrece una economía en expansión. Así lo han parecido ratificar los famosos trabajos de Branko Milanovic, Peter Lindert y Jeffrey Williamson en Gran Bretaña y América durante las fases iniciales de la revolución industrial $(2007,2011)$, o los de Morrison (2000) para Suecia o Prusia. Algunos economistas defienden incluso que este mismo proceso tiene lugar en pleno siglo XXI en algunos países de economías emergentes (Milanovic, Lindert, y Williamson, 2007; Modalsli, 2011). Para la época preindustrial, los trabajos de Van Zanden sobre los Países Bajos en época moderna se han situado en buena medida en esta línea. Él identifica en su momento de despegue económico (anterior a la industrialización) un gran aumento de la desigualdad, que cree que en gran medida venía determinado por la caída de los salarios reales y el crecimiento 
del precio del capital. Un proceso que solamente se revertiría cuando llegara el crecimiento económico "moderno», que eliminaría el exceso de oferta de trabajo (un proceso planteado como una "super curva» de Kuznets) (Van Zanden, 1995; Soltow y Van Zanden, 1998).

Existe, no obstante, una visión diferente a esta, que puede considerarse como la teoría "clásica» sobre la desigualdad, en tanto que se remonta a las obras de David Ricardo, Adam Smith o Karl Marx. Con sus respectivos matices y diferencias, los tres pensaban que el crecimiento económico no reducía, ni en el medio ni en el largo plazo, la desigualdad, sino que la acentuaban: que era un fenómeno consustancial a la industrialización y al capitalismo. Marx y Ricardo coincidían en ver que la desigualdad en una sociedad venía determinada sobre todo por el precio del trabajo en relación al precio del capital². En la actualidad, hay "neoclásicos» que se han centrado en retomar estos argumentos por la vía de la distribución de la riqueza personal. Aunque no es el único, por su reciente impacto tanto en la academia como en los medios de comunicación, Thomas Piketty es probablemente el más conocido. En su estudio de la dinámica del ingreso del $1 \%$ más rico en un gran número de países en el largo recorrido, ha identificado la evolución de la desigualdad en la riqueza como una gran "U» (Piketty 2014) ${ }^{3}$. Desde finales del siglo XVIII hasta la actualidad, la desigualdad en la riqueza parece haber crecido sin parar, con la única excepción del período posterior a las guerras mundiales. Según Piketty, su reducción en esas décadas, que había identificado Kuznets en sus trabajos, era coyuntural, y derivaba de la destrucción de capital de las dos guerras mundiales (Piketty, 2014: 27-29) ${ }^{4}$. La idea a la que se vuelve en la actualidad, gracias a la evidencia de Piketty, es que la desigualdad constituye un hecho consustancial a todo crecimiento económico.

La vuelta a la teoría neoclásica es la oportunidad de oro de los historiadores de la era preindustrial. Transitoria o consustancial al crecimiento, el estudio de la desigualdad en la época medieval y moderna resulta necesaria para entender qué provocaba las grandes diferencias sociales del pasado. Más aún teniendo en cuenta que esto puede estudiarse en períodos históricos, también, de crisis. Esta es quizás una debilidad de los estudios de los economistas, que han teorizado sobre los movimientos de la desigualdad en épocas de bonanza, tratando en menor medida las repercusiones del descenso de la renta per cápita. Además, los medievalistas no solo pueden aproximar el estudio de la desigualdad en la riqueza, sino que lo han

2 Estas reflexiones se las debemos a Ryckbosch, 2014, p. 4.

3 Hay que reconocer que, en los años anteriores a este conocido trabajo, hubo otros autores que elaboraron junto con Piketty parte de estas series de datos sobre ingresos en el largo recorrido. Vid. Piketty, Postel-Vinay, y Rosenthal, 2006; Atkinson, Piketty, y Saez, 2011.

${ }^{4}$ Scheidel (2016) considera que, fundamentalmente, han sido las grandes catástrofes y las crisis de mortalidad las explican episodios de descenso de la desigualdad en el pasado más o menos prolongados en el tiempo. 
hecho tradicionalmente desde indicadores clásicos, con el estudio de los salarios reales, la fiscalidad o la estructura de la propiedad. Ahora bien, los historiadores de época preindustrial también han tratado de estudiar la distribución de la riqueza para la época moderna y, cuando se ha presentado posible, también para la medieval. No solo cabe mencionar al ya mencionado Van Zanden (1995) para el caso de los Países Bajos, sino también los trabajos de Wouter Ryckbosch (2014, 2012) y Jord Hanus $(2014,2013)$ para esta misma región, o los de Guido Alfani (2014, 2010, 2009) sobre las regiones centro-septentrionales de Italia, los de Santiago Caballero sobre España (2011) y, finalmente, los de Reis y Martins sobre Portugal (2012). Hay que reconocer que los medievalistas también se han aproximado al tema de la desigualdad por su propio pie, que ya han calculado coeficientes de Gini ${ }^{5}$ en Inglaterra, Francia y diversas áreas de la Península ibérica (Rubin, 1987; Bekar y Reed, 2013; Sussman, 2006; Slivinski y Sussman, 2009; Ribalta y Turull, 1992; Tello, 1987; Oliva Herrer, 2000a y 2000b).

Los estudios de desigualdad para el período medieval tienen por delante un campo lleno de posibilidades, enmarcadas y apuntaladas por todos estos trabajos. Más aún en el caso de la Península ibérica, especialmente en las zonas de la antigua Corona de Aragón, de donde se han conservado abundantes padrones de riqueza (Furió, 2017) ${ }^{7}$. En general, las diversas contribuciones europeas han podido plantear ya ideas sobre la tendencia que la desigualdad en la riqueza podría haber seguido en diversas áreas del continente entre los siglos XIII y XV. En los casos mejor estudiados, todo parece indicar que la tendencia de la desigualdad era a aumentar, y que solo se interrumpió durante las décadas posteriores a la Peste Negra. En el caso del centro y norte de Italia, de los más estudiados, la desigualdad en 1350 podría haber estado en un coeficiente de Gini del 0,6, siendo 0,5 un siglo más tarde, cuando comenzó a crecer de nuevo entroncando ya con época moderna (en 1550 se recuperan los niveles de 1350, y en 1600 el coeficiente es ya del 0,7) (Ammannati,

${ }^{5}$ Este es el método más recurrido para el estudio de la desigualdad económica, el cual se introducirá con mayor detalle en el apartado 2.

${ }^{6}$ Hay que mencionar, además, el proyecto financiado por el Ministerio de Educación y Ciencia del Gobierno de España («Crecimiento económico y desigualdad social en la Europa mediterránea, siglos XIII-XV», HAR2014-58730-P), que se desarrolla en la actualidad en la Universitat de València bajo la dirección de Antoni Furió. Del mismo autor, igualmente, Furió, 2015. El proyecto retoma los esfuerzos de la primera generación de la escuela valenciana en aproximar el tema de la desigualdad, por ejemplo, con los trabajos del propio Antoni Furió (1982), pero también de Pau Viciano (1997).

${ }^{7}$ Las fuentes que registran impuestos directos sobre la riqueza, en general, se conservan de manera muy desigual en el panorama europeo y, además, concentradas en el período moderno o en las últimas décadas de la Edad Media. Vid. Alfani, 2014, Hanus, 2013; Santiago Caballero, 2011; Alfani, 2010; Van Zanden, 1995. 
De Franco y Di Tullio, 2014, p. 21) ${ }^{8}$. Es un proceso parecido al del sur de los Países Bajos, con una desigualdad del 0,5 en las últimas décadas del siglo XIV, un nivel aún similar a finales del siglo XV, y aún más bajo en las primeras décadas del XVI (cerca del 0,35), cuando comenzó a crecer ya sin parar (Ryckbosch, 2014, p. 17) ${ }^{9}$. En el caso de Inglaterra es difícil aportar visiones del conjunto del territorio, incluso a nivel regional, por la escasez de fuentes. En el largo recorrido, no obstante, se puede documentar un aumento de la desigualdad entre 1290 y 1688, que habría pasado de un coeficiente de Gini del 0,37 al 0,49 (Broadberry, et al., 2015, p. 308), si bien es muy posible que el período posterior a la peste viniera acompañado de un descenso de la desigualdad, teniendo en cuenta la tendencia de los salarios reales ${ }^{10}$.

En general, la idea para el período medieval es que la relación entre crecimiento económico y desigualdad es fundamentalmente directa: en momentos de depresión la desigualdad se suavizaba, y en los de auge aumentaba. Las dificultades de acceso a la tierra, el capital, la educación o el poder político contribuían a que las desigualdades vinieran marcadas desde el nacimiento y se perpetuaran generación tras generación (Broadberry, et al., 2015, p. 307). ¿Qué ocurrió en los reinos medievales hispánicos? En principio, parece plausible pensar que las dinámicas de la desigualdad en la riqueza se hubieran desarrollado de manera diferente. Al contrario que los casos europeos citados, buena parte de los reinos ibéricos se habían creado bajo procesos de conquista y llegada de nuevos pobladores durante la plena Edad Media. El acceso al capital -como a la propia tierra, por ejemplo- era mucho más fácil que en otros lugares del continente, sobre todo en el siglo XIII, y la movilidad social era muy intensa. Ahora bien, las evidencias que se tienen hasta el momento corresponden fundamentalmente al siglo $x V y$, cuando se presenta posible, a la segunda mitad del siglo XIV, y muestran un panorama similar al del continente. En el reino de Valencia, Antoni Furió (2015) ha podido documentar cómo el aumento de la desigualdad es constante en el período bajomedieval, solo interrumpido durante la segunda mitad del siglo xIV.

En este sentido, nuestra contribución pretende añadir nuevas evidencias para el estudio de la desigualdad en el caso de la baja edad media hispánica. Se trata de una aproximación a través de una investigación en curso sobre el tema, dirigida desde la Universitat de València por el profesor Antoni Furió, y que pretende estudiar poblaciones de toda la Península ibérica y las Islas Baleares,

${ }^{8}$ El dato corresponde a la ciudad piamontesa de Cherasco, pero los autores consideran que hay evidencias, al menos de época moderna, de tendencias similares, por en ejemplo, en casos toscanos como el de Prato (Ídem, p. 26).

${ }^{9}$ Las regiones del norte de los Países Bajos presentan una tendencia parecida a la general, pero el autor no ha podido proporcionar datos anteriores al siglo XVI.

${ }_{10}$ Los historiadores aceptan que los salarios reales ingleses aumentaron sustancialmente en el período posterior a la peste de 1348 , si bien recientemente se ha matizado mucho su magnitud. Hatcher, 2011, pp. 1-24; Broadberry, et al., 2015, pp. 257-260. 
desde Portugal o el País Vasco a Valencia, Cataluña, Aragón y Mallorca, pasando por Castilla. Aunque quisiéramos, no podemos todavía aportar una cantidad de datos suficiente como para proponer dinámicas cronológicas, debido al estadio inicial del proyecto. No obstante, con este trabajo nos proponemos realizar un pequeño ensayo del mismo explicando el tipo de fuente y método utilizado, así como algunos resultados de carácter provisional. En concreto, presentamos tasas de desigualdad, valoradas a partir del coeficiente de Gini y la distribución de la riqueza por deciles, correspondientes a tres localidades hispánicas en el contexto bajomedieval: Valls, Sevilla y Palma ${ }^{11}$. La primera parte de este trabajo discute las fuentes utilizadas, sus límites y características. La segunda presenta los fundamentos del método seguido y sus particularidades al utilizarse en el estudio de sociedades bajomedievales. La tercera analiza los resultados obtenidos en estas tres localidades para explorar diferencias entre grupos socioprofesionales, entre ciudad y campo y de género.

\section{LAS FUENTES PARA EL ESTUDIO DE LA DESIGUALDAD EN LA RIQUEZA DURANTE EL PERÍODO BAJOMEDIEVAL}

La posibilidad de establecer indicadores numéricos que reflejen la desigualdad económica se basa, en gran medida, en las fuentes que se utilicen. El coeficiente Gini fue creado para cuantificar numéricamente la desigualdad empleando para ello fuentes contemporáneas que proporcionan datos muy concretos sobre los niveles económicos de una sociedad. Sin embargo, este coeficiente también se puede aplicar para medir distintos tipos de distribución desigual a lo largo de la historia, siempre y cuando se cuente con las fuentes adecuadas.

Para la historia económica medieval, se dispone de fuentes fiscales que registraron, en diferentes momentos y por razones diversas, la riqueza patrimonial de la población y la cantidad que debían aportar, dependiendo de sus posibilidades, a la naciente fiscalidad de estado o municipal. No obstante, no todas las fuentes son útiles para nuestro empeño y solo aquellas en que la tasación impuesta a pagar se haya asignado de manera proporcional, es decir, solo aquellas en las que se tuviera en cuenta la riqueza de cada individuo antes de tasarlo, serán viables para su utilización. La medición de la desigualdad no será posible en aquellos casos en los que la recaudación mantiene una tasa fija, recaudando la misma cantidad para cada contribuyente, o que la proporcionalidad sea grosera, dividiendo, por ejemplo, los contribuyentes en tres grandes grupos. Por lo tanto, para adoptar el coeficiente Gini

${ }^{11}$ A lo largo del artículo nos referiremos al antiguo municipio de Palma de Mallorca como Palma, nombre oficial desde noviembre de 2016, aunque durante la Edad Media la capital mallorquina era conocida por Ciutat de Mallorca o Ciutat de Mallorques. 
en nuestros estudios precisamos de unas fuentes que muestren la proporcionalidad directa entre patrimonio personal y el impuesto a pagar.

El impuesto directo proporcional al patrimonio apareció en el norte de Italia en el siglo XII, como consecuencia de la recuperación de prácticas y conceptos jurídicos propios del derecho romano que las comunas italianas estaban rescatando para desarrollar sus incipientes entidades políticas. Desde Italia, el impuesto directo se extendió por las costas mediterráneas llegando a Toulouse, Montpelier y, finalmente, a la Corona de Aragón, ya en el siglo XIII. La rápida extensión de esta forma de tributación se debe, como afirma Antoni Furió (2017), a que los municipios mediterráneos no solo cuentan con un tamaño mayor, con más habitantes, más diversificación y especialización profesional, sino que estos partían de una cultura fiscal común, en técnicas, procedimientos, conceptos y fundamentos jurídicos. Su extensión continuaría desde la Corona de Aragón hacia tierras castellanas a través de su implantación en ciudades como Murcia y Sevilla.

Para describir la naturaleza y el contenido de estas fuentes fiscales en la Península ibérica es necesario señalar que las más antiguas son, en su mayoría, de carácter extraordinario, y que están muy vinculadas al gasto militar propio de las necesidades de una contienda bélica específica. Un sistema fiscal ordinario, permanente y estable, no se desarrolló hasta bien entrado el siglo XIV, por lo que anteriormente a esta fecha los impuestos eran recaudados con una finalidad concreta, ya fuese una demanda de la corona, normalmente por una emergencia militar, o necesidad de liquidez municipal. A veces el impuesto directo era suavizado bajo la fórmula de un préstamo forzado, como en Italia, que aunque seguía los mismos mecanismos de recaudación, incluía la promesa de devolver la suma tomada en préstamo en el plazo de dos años, aunque la frecuente insolvencia de la ciudad difería, a veces sine die, la restitución del mismo (Furió, 2017).

La carga fiscal recaía sobre todos los habitantes del municipio, dejando exentos a la nobleza y a los eclesiásticos, puesto que su posición privilegiada en la sociedad estamental los mantenía fuera de la presión fiscal, en la mayoría de los casos. Dicha carga era repartida entre los habitantes sujetos a tributación, según el valor de su patrimonio. Para la gestión del impuesto y establecer la cantidad a pagar por cada individuo fiscalizado, los municipios realizaban unos registros en los que se especificaba los bienes de cada contribuyente y, así, se podía estimar un valor para su patrimonio. En el siglo XIII, la declaración y estimación de los bienes todavía se basaba en la declaración de los propios contribuyentes, pero para mejorar el sistema y evitar posibles ocultaciones, desde principios del siglo xIV esta misión fue confiada a una comisión encargada del asunto. En el caso de la ciudad de Valencia se escogían de dos a cuatro prohombres por cada parroquia, que se encargarían de estimar el valor imponible de los bienes de sus vecinos (García Marsilla, 1996, pp. 149-172). Sin embargo, estas fuentes pueden tener limitaciones que hay que tener en cuenta en su aplicación en la metodología del coeficiente de Gini. La 
limitación fundamental es que las fuentes fiscales pueden no registrar a la totalidad de los habitantes de la ciudad. Como ya hemos enunciado, en muchos casos hay determinados grupos que no aparecen en la fuente como la nobleza y el clero, pero también judíos, musulmanes, extranjeros y aquellos que no tenían la suficiente capacidad económica como para ser tasados (nichil). Sin embargo, esto no quita su utilidad para realizar unos cómputos sobre la desigualdad medieval.

En este sentido, producto de la evolución y diversidad en la naturaleza del impuesto directo solicitado, encontramos distintas las tipologías aplicables para nuestro empeño, tales como padrones de riqueza, quèstia, talla, peita, llibre d'estimes, libros de cuantías, amillaramientos, entre otros. Todas estas fuentes, encargadas de calcular a partir del valor patrimonial de los bienes de un individuo una tasa concreta de tributación, pueden ser utilizadas para obtener el coeficiente de Gini de una población medieval.

Con el fin de mostrar las posibilidades y límites de nuestro proyecto y, sobre todo, algunos resultados preliminares para realizar una primera contribución al estudio de la desigualdad en la Baja Edad Media, hemos seleccionado tres casos concretos: Sevilla, Valls y Palma. Se trata de algunas de las localidades que forman parte del proyecto de investigación sobre desigualdad económica en la Península ibérica, desarrollado desde la Universitat de València, y que aglutina muchos más casos y áreas. A continuación, pasamos a explicar las particularidades de las fuentes estudiadas.

El primer caso es el libro de cuantías de los vecinos y moradores de los barrios y collaçiones de Sevilla, realizado en 1384, cuyo contenido ha podido consultarse gracias a la transcripción realizada por M. Álvarez, M. Ariza, J. Mendoza y A. Collantes de Terán (2001) ${ }^{12}$. Este es el primer padrón ${ }^{13}$ que se ha conservado y el único del período medieval, que abarca todas las circunscripciones administrativas de la ciudad, con excepción de la judería. Los posteriores son cuadernos por parroquia o barrio, y no todos han llegado hasta nuestros días. Esto no significa que se trate de una fuente completa, ya que no figuran en la misma los eclesiásticos y la gran mayoría de los pobres. La confección del padrón se produjo en el contexto de la guerra entre Portugal y Castilla, derivada del conflicto dinástico planteado a la muerte del monarca portugués Fernando I en 1383. Por su matrimonio con la infanta portuguesa Beatriz, Juan I de Castilla quiso hacer efectivo su gobierno sobre Portugal, por lo que contaría con el apoyo de la nobleza portuguesa, mientras que otro sector se opusieron, encabezados por don Juan, maestre de Avís, iniciándose ente ambos bandos una importante contienda militar (Álvarez, et al., 2001).

12 La referencia original de la fuente es: Archivo Municipal de Sevilla, secc. XVI, doc. 14.

13 Para la denominación de la fuente, seguiremos la pauta establecida por Antonio Collantes de Terán Sánchez, autor del estudio histórico de la misma, utilizando «padrón» y no «libro de cuantías». Álvarez, et al., 2001, pp. 11-20. 
En el padrón aparecen las 25 parroquias o collaciones, de las cuales todas son eclesiásticas a excepción de Triana, al otro lado del río Guadalquivir. Dentro de cada una de las circunscripciones, el vecindario se encuentra dividido en tres categorías: los caballeros, francos y pecheros. Los caballeros eran un colectivo amplio en el que se integran tanto grandes nobles, hidalgos como "cuantiosos», los sectores ciudadanos capaces de mantener un caballo. El grupo de los francos lo integraban aquellos que a pesar de no ser nobles gozaban de una serie de privilegios fiscales, por lo que estaban exentos de algunos impuestos o servicios. Finalmente, los pecheros son aquellos obligados a contribuir sin ningún tipo de exención fiscal.

En segundo lugar, hemos trabajado la villa de Valls, en la actual provincia de Tarragona. La fuente trabajada ha sido el libro de estimes de 1378, cuyo contenido ha sido publicado y sistematizado por J. Morelló, y que registra 542 contribuyentes $^{14}$. 25 de ellos quedaron exentos bajo la condición de nichil, con lo que solo los 517 restantes pueden estudiarse de cara a medir los índices de desigualdad. De todos ellos, cerca de un 16\% (86 individuos) eran mujeres, que normalmente quedan identificadas por su vínculo con un varón como hijas, suegras o mujeres o viudas. 9 de ellas eran nichil, lo que deja un elenco de 77 . Por otra parte, 10 de estos individuos residían en el call o judería. El padrón también recoge la contribución de poblados pertenecientes al término de Valls, como Fontscaldes (12 contribuyentes), Masmolets (17), Picamoixons (10) y Espinavessa (6). Por cuestiones de representatividad, estos individuos se han apartado de la muestra estudiada, que se centra así en la población de la propia Valls. La posibilidad de realizar un análisis de deciles o de extraer el coeficiente de Gini de estos lugares tampoco parece estadísticamente viable, ni siquiera de manera conjunta, al tratarse solo de 45 individuos.

La fuente incluye la estimación del patrimonio mueble e inmueble de los individuos, así como el de la deuda censal, y la cuota de la talla que hubo de pagarse. Este último aspecto ha sido el que ha interesado a Jordi Morelló, que ha estudiado la fiscalidad de la villa desde los años 1990. Para este trabajo, se ha tomado únicamente el total de la estimación, utilizando la valoración total de todo el patrimonio, que normalmente viene en el propio padrón. Como se ha especificado más arriba, la mayoría de los contribuyentes eran varones, pero la cantidad significativa de mujeres permite estudiar los niveles de desigualdad en ellas. Por otra parte, la fuente raramente especifica la extracción profesional de los contribuyentes, salvo en casos aislados.

Por último presentaremos el caso de la ciudad de Mallorca, actual Palma. Para ello contamos con la Talla general de la ciutat de Mallorca del año 1478 que, en la actualidad, se conserva en el Archivo del Reino de Mallorca, registro inédito que se ha consultado in situ para establecer las comparaciones propicias con los casos

${ }^{14}$ Morelló, 2003, pp. 37-74. 
mencionados con anterioridad ${ }^{15}$. La fuente está dividida en cinco parroquias $y$, dentro de cada parroquia, en manzanas, que vienen designadas con un nombre, normalmente el del contribuyente más pudiente. De los contribuyentes se suele indicar la profesión, aunque no en todas las ocasiones. Como en el resto de casos, la mayoría de los individuos tasados son hombres, ya que solo aparecen 412 mujeres de un total de 2.606 contribuyentes. La fuente, como en el caso de Sevilla, sí que incluye caballeros, quienes, sorprendentemente, no eran los que mayor cantidad de bienes atesoraban.

Aunque fuentes de naturaleza y características diferentes, todas ellas miden de manera proporcional la tasación pagada en relación con los bienes poseídos, lo que hace posible el estudio del coeficiente de Gini y la distribución de la riqueza por deciles. De este modo, pasamos a explicar las líneas metodológicas que con las que hemos trabajado.

\section{NUESTRA PROPUESTA METODOLÓGICA}

El cálculo de la desigualdad económica en la Baja Edad Media es una operación compleja y que requiere unos firmes anclajes metodológicos para asegurar el éxito de la empresa. Como grupo de investigación, nos fijamos enseguida la necesidad de compartir unos criterios metodológicos comunes con el fin de poder comparar los resultados que íbamos obteniendo en cada población estudiada.

Comenzamos elaborando una ficha de Excel que nos ha servido como modelo en la recogida de la información de todos los lugares estudiados en la Península ibérica y las Islas Baleares. La hoja Excel recoge la información que consideramos de sensible interés para el trabajo. En ella se refleja la presencia de todos los individuos que vienen reflejados como contribuyentes o a los que se les censa su riqueza. Comenzamos dedicando la primera columna a la parroquia en la que vive la persona, la segunda la utilizamos para reflejar su condición socioprofesional, en el caso de que la fuente nos permita conocerlo. A continuación insertamos nombre y apellido del contribuyente, el género y la profesión, si la tenemos, y el valor de sus propiedades y la cantidad con la que contribuye a la satisfacción del impuesto.

El caso que presenta una riqueza más genuina respecto al resto de municipios estudiados es el de Sevilla, puesto que en la fuente de la capital andaluza aparecen tanto pecheros como nobles en el pago del impuesto reclamado. Por otra parte, tenemos también el caso de Mallorca, donde también aparecen unos poco individuos que la fuente refleja como caballeros.

Una decisión que hemos debido abordar, por la tipología de las fuentes que estudiamos, es el dejar fuera del estudio a las instituciones que en algunas de

\footnotetext{
${ }^{15}$ La referencia del registro es Arxiu del Regne de Mallorca, AH-2100.
} 
las fuentes estudiadas vienen reflejadas de igual modo que los contribuyentes individuales. Se decidió así puesto que el objetivo que por ahora persigue el grupo de investigación es la medición de la desigualdad entre personas físicas o familias.

Otra peculiaridad a la que nos hemos enfrentado es la presencia de población extranjera en las fuentes. Estos individuos han sido descartados en la obtención de resultados con la intención de no generar un sesgo en el estudio, aunque figuran en las bases de datos, ya que es presumible que esta parte de la población tuviera parte de sus bienes en un lugar diferente al municipio que estamos estudiando.

Una vez hemos construido nuestra base de datos, realizamos una ordenación de los individuos según la cuantía declarada o pagada, de menor a mayor. Cuando tenemos ordenados a todos los contribuyentes por su riqueza, en el orden anteriormente descrito; los agrupamos en diez conjuntos, en lo que llamamos deciles. En los casos en los que no ha sido posible la división del número de sujetos entre diez y que se obtuviera un número entero hemos sumado las personas sobrantes en los grupos más pobres de menor a mayor. Por ejemplo, en el caso de que hubiera 103 declarantes, los deciles que confeccionamos quedarían de menor a mayor: $11,11,11,10,10,10,10,10,10$ y 10 . Hemos tomado esta decisión porque consideramos que, entre las diferentes variables que se podían adoptar ante esta vicisitud, es la que menos riesgo tiene de alterar los resultados.

Una vez confeccionados los deciles como se ha expuesto anteriormente, hemos procedido a trabajar con ellos calculando el porcentaje de riqueza de cada conjunto de cada $10 \%$ de la población, desde el $10 \%$ más pobre al más rico. En los casos en los que los deciles más ricos representan un gran porcentaje de la riqueza total, hemos juzgado oportuno calcular también la riqueza del $5 \%$ y la del $1 \%$.

Tabla 1. Distribución de la riqueza por deciles de las tres localidades estudiadas

\begin{tabular}{|l|l|l|l|l|l|l|l|r|r|c|}
\hline & D1 & D2 & D3 & D4 & D5 & D6 & D7 & \multicolumn{1}{|c|}{ D8 } & \multicolumn{1}{c|}{ D9 } & D10 \\
\hline Valls (1378) & 0,53 & 1,10 & 1,71 & 2,51 & 3,55 & 5,66 & 7,96 & 11,33 & 18,28 & 47,31 \\
\hline Sevilla(1384) & 1,04 & 1,06 & 2,07 & 2,12 & 2,12 & 3,09 & 4,24 & 5,93 & 10,07 & 68,26 \\
\hline Sevilla(1384)* & 2,63 & 2,69 & 3,84 & 5,39 & 5,39 & 5,39 & 6,65 & 10,59 & 13,84 & 43,56 \\
\hline Mallorca (1478) & 1,38 & 1,92 & 2,42 & 3,13 & 3,13 & 3,96 & 4,99 & 9,13 & 14,89 & 56,01 \\
\hline
\end{tabular}

Notas: Los deciles de Sevilla con * corresponden a la distribución de la riqueza en esta población excluyendo los contribuyentes del estamento nobiliario (véase el texto).

En este tabla se muestra el porcentaje de riqueza acumulado por cada uno de los deciles de la población. Se observa como el D1, corresponde al 10\% más pobre de la población y los siguientes deciles se muestran por orden de menor a mayor hasta llegar al D10, que representa al $10 \%$ más rico. 
Gráfica 1. Distribución de la riqueza por deciles

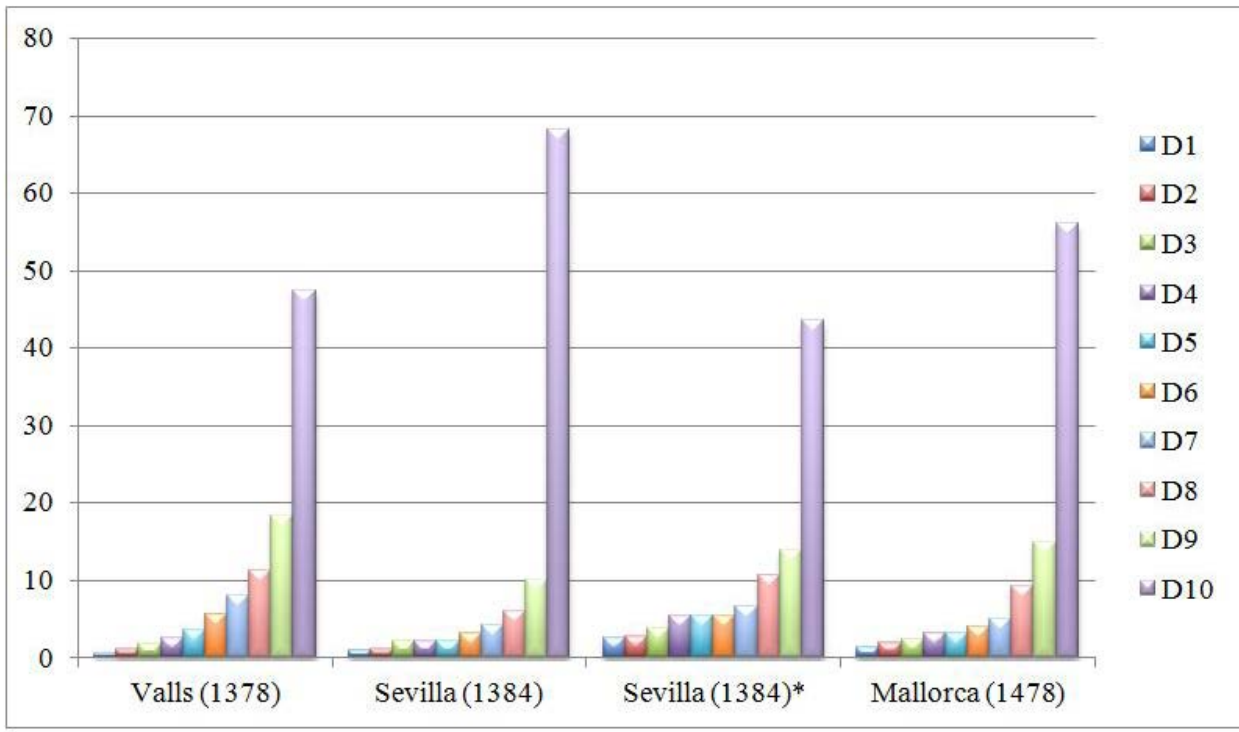

Notas: Los deciles de Sevilla con * corresponden a la distribución de la riqueza en esta población excluyendo los contribuyentes del estamento nobiliario (véase el texto).

Los grupos de personas más ricas han sido objeto de un posterior análisis pormenorizando en el cual hemos estudiado qué personas componían estos grupos de notables en cada uno de los municipios estudiados. Así, nos hemos fijado en el total de su riqueza en valores absolutos y relativos y, sobre todo, en la composición del propio decil en base a la condición social y a la profesión que desempeñaban estos notables.

A continuación, hemos extraído de las bases de datos otros parámetros que juzgábamos importantes en la mediación de la desigualdad económica y su posterior comparación. Empezamos calculando la media de riqueza del conjunto de los habitantes del municipio estudiado. A continuación, para descartar las posibles interferencias que pudieran producirse por la existencia de alguna enorme fortuna, decidimos pasar a calcular la mediana del conjunto de cantidades que figuran en la base de datos. Por último, juzgamos asimismo interesante el cálculo del valor máximo y mínimo aparecidos en la fuente.

Los deciles confeccionados combinados con el número total de casos que integran el decil nos han servido como base para calcular el coeficiente de Gini. Este coeficiente es una medida de concentración del ingreso entre los individuos de un municipio o territorio, en un determinado periodo. Esta medida está ligada a la Curva de Lorenz, que mide de igual forma las desigualdades económicas en un 
grupo poblacional de forma gráfica. El coeficiente de Gini tiene como resultado un valor entre 0 y 1 , donde 0 indica que todos los individuos tienen la misma riqueza y 1 indica que solo un individuo concentra toda la riqueza del grupo estudiado. Así, el coeficiente de Gini es la herramienta que mejor mide en la actualidad el grado de desigualdad de la distribución de la riqueza en un municipio o una región del presente o histórico.

Tabla 2. Coeficientes de Gini, valores medios, mínimos y máximos

\begin{tabular}{|l|r|r|r|r|r|}
\hline & Gini & Media & Mediana & Mínimo & Máximo \\
\hline Valls (1378) & 0,665 & $1.710 \mathrm{~s}$. & $795 \mathrm{~s}$. & $20 \mathrm{~s}$. & $29.075 \mathrm{~s}$. \\
\hline Sevilla(1384) & 0,805 & $471 \mathrm{mr}$. & $100 \mathrm{mr}$. & $50 \mathrm{mr}$. & $50.000 \mathrm{mr}$. \\
\hline Sevilla(1384)* & 0,589 & $185 \mathrm{mr}$. & $100 \mathrm{mr}$. & $50 \mathrm{mr}$. & $10.000 \mathrm{mr}$ \\
\hline Mallorca (1478) & 0,723 & $19,15 \mathrm{~s}$. & $6 \mathrm{~s}$. & $1 \mathrm{~s}$. & $800 \mathrm{~s}$. \\
\hline
\end{tabular}

Notas: Los deciles de Sevilla con * corresponden a la distribución de la riqueza en esta población excluyendo los contribuyentes del estamento nobiliario (véase el texto); $\mathrm{mr} .=$ maravedís; $\mathrm{s}$ = sous.

En esta tabla se aprecia el coeficiente de Gini para los tres casos estudiados con su correspondiente año analizado. Se puede ver el resultado en una horquilla entre el 0 , donde existiría la igualdad absoluta, y el 1 , donde todos los recursos económicos pertenecerían a una sola persona.

Gráfica 2. Coeficientes de Gini de las localidades estudiadas

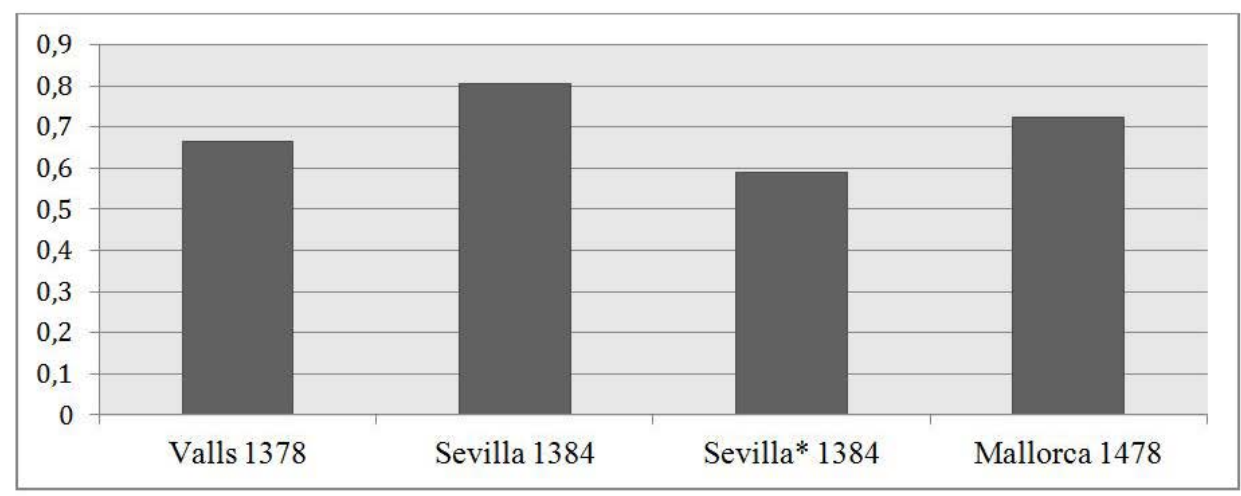

Notas: Los deciles de Sevilla con * corresponden a la distribución de la riqueza en esta población excluyendo los contribuyentes del estamento nobiliario (véase el texto).

Además, nos ha parecido interesante medir otras desigualdades más específicas dentro de las sociedades estudiadas a partir de la base de datos general que hemos confeccionado. En primer lugar, nos planteamos la importancia de 
medir la desigualdad económica entre las mujeres declarantes o contribuyentes en estos municipios trabajados. Discriminando a los hombres de la ecuación, volvemos a ordenador a las mujeres por su riqueza de menor a mayor y construimos unos nuevos deciles donde únicamente contemplamos a las mujeres que tenemos en las bases de datos. De esta manera, conseguimos establecer la desigualdad económica entre las mujeres del municipio.

De la misma manera, hemos considerado que era importante analizar de forma pormenorizada algunas desigualdades económicas dentro de una misma categoría profesional o una agrupación de ellas. Así, hemos procurado seleccionar profesiones con un número representativo de miembros fiscalizados en la fuente.

Por último, pretendemos calcular también la desigualdad a nivel espacial entre las diferentes parroquias de los municipios. De esta manera puede explorarse si existía una concentración socio espacial dentro de la ciudad medieval o, por el contrario, los diversos grupos sociales se hallaban entremezclados con independencia de su nivel de riqueza. Con esta finalidad, hemos utilizado los datos de la columna de las parroquias de nuestra base de datos y hemos construido unos nuevos deciles donde solo aparecen los habitantes de cada parroquia. Esto nos ha permitido dividir geográficamente la ciudad entre sus diferentes barrios y calcular la desigualdad económica de cada uno para después compararlos con el resto de barrios de su propio municipio. Esta labor se ha podido llevar a cabo de forma más sistemática y consistente en Palma y Sevilla.

\section{ESTUDIO DE CASOS: ALGUNOS RESULTADOS PROVISIONALES}

Lo primero que podemos analizar es la desigualdad por parroquias y grupos socioprofesionales. En el caso de la ciudad de Palma, la fuente recoge cinco parroquias diferentes para el municipio balear: Santa Eul-làlia, Sant Jaume, Santa Creu, Sant Nicolau y Sant Miquel. Todas ellas se encontraban en el interior de la muralla palmesana, intentando resguardarse de los ataques costeros que pudieran producirse en toda la isla.

Tabla 3. Niveles de desigualdad en las parroquias de Palma (1478)

\begin{tabular}{|l|c|c|c|c|c|}
\hline & Gini & Media (s) & Mediana (s) & Mínimo (s) & Máximo (s) \\
\hline Santa Eulàlia & 0,685 & 16,59 & 6 & 1 & 400 \\
\hline Sant Jaume & 0,675 & 24,11 & 8 & 2 & 400 \\
\hline Sant Nicolau & 0,720 & 18,85 & 6 & 1 & 680 \\
\hline Santa Creu & 0,793 & 26,82 & 6 & 1 & 800 \\
\hline Sant Miquel & 0,564 & 9,42 & 6 & 1 & 360 \\
\hline General & 0,723 & 19,15 & 6 & 1 & 800 \\
\hline
\end{tabular}

Notas: $\mathrm{s} .=$ sous . 
De todas ellas, la que presenta una media de riqueza más elevada es la de Santa Creu, con 26,82 sous. Santa Eul·làlia se situaba en el corazón de la Palma medieval, en ella se encontraban los principales edificios religiosos y administrativos. Asimismo, destacaba por su carácter heterogéneo, al ubicarse en su interior una zona desde las que se dirigía la ciudad, el call major (judería), y una zona de curtidores como el barrio de Calatrava. Es la que tiene una mayor desigualdad económica interna con un 0,793 debido a la gran heterogeneidad que hemos comentado. A continuación, por media de riqueza aparece la parroquia de Sant Jaume, que no es la que tiene el segundo coeficiente de Gini, sino que en este aspecto está en el cuarto lugar de las cinco parroquias. Este aspecto se debe a que este era el barrio de residencia de las élites urbanas junto con algunas calles de Santa Eul·làlia y Santa Creu (Barceló, 1985, pp. 1322-1324).

La segunda máxima desigualdad, siguiendo el índice de Gini, se halla en la parroquia de Sant Nicolau. Este era el barrio que albergaba el mercado municipal de los sábados, y aunque se ha especulado con que fuera el de residencia habitual de los pelaires, sabemos que estos estaban repartidos por toda la ciudad y con mayor intensidad en Santa Eul-làlia. Sin embargo, Sant Nicolau tiene una riqueza media de tan solo 18,85 sous, muy cerca de Santa Eul·làlia, con 16,59 sous, que tiene un coeficiente de Gini muy cercano al de Sant Jaume. Prácticamente seis puntos por debajo de Santa Eul-làlia en riqueza media tenemos a la parroquia de Sant Miquel, que además de la más pobre también es la más igualitaria económicamente con tan solo un 0,564 de desigualdad en el interior de la parroquia (recordemos que la desigualdad media de todo el municipio se sitúa en el 0,723$)$. Sant Miquel era una parroquia poco poblada, puede ser porque estuviera junto a la muralla donde se ubicaban una serie de huertos (Barceló, 1985, pp. 1324-1325).

A la mediana no haremos demasiada referencia porque es exactamente el mismo valor para todas y cada una de las parroquias; en cambio, la mínima y el máximo sí que registran algunas diferencias interesantes. En cuanto a las mínimas, en todas las parroquias, las persona que menos contribuía lo hacía con tan solo un sou, menos en la de Sant Jaume, que lo hacía con 2. En cuanto a las máximas, sí existen mayores variaciones, ya que tenemos desde los 360 sous que paga el contribuyente más acaudalado de San Miquel, la parroquia más pobre y más igualitaria, hasta los 800 sous que paga la contribuyente más rica de Santa Creu, la parroquia más rica y más desigual.

Pasando ahora al análisis de los resultados de las tablas relacionadas con la profesión para la ciudad insular, hemos de indicar en un primer momento que los trabajadores recogidos han sido: notarios, pelaires, mercaderes y tejedores. Tomados como ejemplo por su elevado número de contribuyentes y por sus diferencias socioprofesionales. 
Tabla 4. Niveles de desigualdad entre sectores profesionales de Palma (1478)

\begin{tabular}{|l|c|c|c|c|c|}
\hline & Gini & Media (s) & Mediana (s) & Mínimo (s) & Máximo (s) \\
\hline Notarios & 0,296 & 18,76 & 15 & 4 & 55 \\
\hline Pelaires & 0,421 & 3,37 & 6 & 2 & 60 \\
\hline Mercaderes & 0,640 & 38,22 & 20 & 3 & 400 \\
\hline Tejedores & 0,203 & 5,58 & 6 & 3 & 16 \\
\hline General & 0,723 & 19,15 & 6 & 1 & 800 \\
\hline
\end{tabular}

Notas: $\mathrm{s} .=$ sous.

Hay que destacar la mayor riqueza media de los mercaderes y un grado mayor de desigualdad en este sector profesional. Además, es el grupo en el que más diferencia hay entre el contribuyente más rico y el más pobre: de 3 a 400 sous. Hemos de pensar en los mercaderes eran un oficio muy diverso que podía concentrar desde pequeños comerciantes a escala local o regional a hombres que realizaran sus negocios en un marco internacional.

Desde la riqueza media de los mercaderes, 38,22 sous, descendemos según la media a los 18,76 sous de los notarios, situándose también la mediana en 5 sous por debajo de los mercaderes: de los 20 a los 15 sous. Sin embargo, los notarios ocupan la segunda posición de mayor igualdad con un 0,296 , solo superados por los tejedores, con un 0,203 , pero siendo estos más pobres de media, ya que se quedan en un 5,58 sous.

Por último, tanto en media de riqueza como en igualdad se sitúan los pelaires, con una riqueza media de 3,37 y con una gran desigualdad, en relación con su escasa riqueza media, de un 0,421 , justo en la mitad entre mercaderes y notarios, siendo ambos dos veces más ricos de media que los pelaires. Estos sí tienen una mediana de riqueza que coincide con la media de todas las parroquias y de los tejedores: 6 sous, apreciando así que eran el grupo más ricamente distribuido por toda urbe mallorquina. En cuanto al mínimo y al máximo, la profesión que más distancia registra entre estos dos índices es la de mercader, que tiene un mínimo de 3 y un máximo 400 sous, seguida de la de pelaire, con un mínimo de 2 y un máximo de 60 sous. Por su parte, los notarios tienen de mínima 4 sous y de máxima 55 , mientras que entre los tejedores la diferencia es la menor de todas, y se sitúa en un mínimo de 3 y un máximo de 16 sous. Estos resultados pueden estar determinados porque los notarios y los tejedores son las dos profesiones con una mayor reglamentación interna, lo que podría haber favorecido la igualdad en su seno.

Cambiando ahora de municipio, pasamos a estudiar diferentes ámbitos socioeconómicos en el caso de Sevilla. En esta ocasión, estudiaremos a los caballeros, los escribanos, los carniceros, los pescadores y los tejedores. Los caballeros no son ningún grupo profesional, pero sí social, y nos ha parecido importante tenerlos en cuenta en este caso, ya que es la única fuente que los recoge consistentemente. 
Tabla 5. Niveles de desigualdad entre sectores profesionales de Sevilla (1384)

\begin{tabular}{|l|c|c|c|c|c|}
\hline & Gini & Media (mr.) & Mediana (mr.) & Mínimo (mr.) & Máximo (mr.) \\
\hline Caballeros & 0,793 & $1.665,56$ & 300 & 50 & 50.000 \\
\hline Escribanos & 0,491 & 352,72 & 200 & 50 & 2.000 \\
\hline Carniceros & 0,386 & 197,61 & 200 & 50 & 500 \\
\hline Pescadores & 0,363 & 115,44 & 100 & 50 & 500 \\
\hline Tejedores & 0,437 & 123,80 & 100 & 50 & 400 \\
\hline General & 0,805 & 471 & 100 & 50 & 50.000 \\
\hline
\end{tabular}

Notas: $\mathrm{mr} .=$ maravedís.

Empezando por los mismos caballeros, debemos indicar que es el grupo que tiene mayor riqueza media, con 1.665,56 maravedís, mayor desigualdad dentro del grupo, una mediana mayor con 300 maravedís y un máximo mayor con 50.000 maravedís. Este hecho no puede extrañarnos en la sociedad castellana del siglo xIV. De ahí pasamos a los escribanos, que tienen una media de 352,72 maravedís de riqueza media, un 0,491 de desigualdad, una mediana de 200 maravedís y un máximo de 2.000 maravedís. Les siguen los carniceros, con una riqueza media de 197,61 maravedís, una desigualdad de 0,386, la misma mediana que los escribanos y un máximo de 500 maravedís.

El penúltimo grupo en cuanto a riqueza media son los tejedores, con un 123,80 maravedís, pero con una desigualdad mayor que la de los carniceros, con un 0,437, su mediana será igual que la de los pescadores y su máximo será en menor de todas las profesiones. Por último, aparecen los pescadores con solo 115,44 maravedís de riqueza media, la menor desigualdad también con un 0,363 , la menor mediana junto a la de los tejedores y un máximo igual que el de los carniceros. Estos resultados vuelven a confirmar la hipótesis que aquello que más desigualdad provoca es la riqueza, no la pobreza, viendo así cómo el grupo más rico es el más desigual y el más pobre el más igualitario. En esta ocasión no hemos hecho referencia al mínimo de cada grupo porque la pecha fijaba en todos los casos un mínimo de 50 maravedís, mínimo que es común a los cinco grupos estudiados.

Otro aspecto al que contribuir con las fuentes estudiadas es el de las diferencias entre ciudad y campo. Esta es una de las dimensiones que revisten de un mayor interés para nuestro proyecto, y que aquí podemos abordar desde el punto de vista de la villa de Valls. Hay que precisar, como es recurrente al abordar todo contraste campo-ciudad, que no existen núcleos completamente rurales ni urbanos. Sevilla y Palma eran grandes capitales regionales y políticas que, tanto en sus arrabales como dentro de sus murallas, acogían familias de campesinos. Lo mismo ocurre en el medio rural, en el que no todos sus habitantes se dedicaban plenamente al trabajo agrario. En el caso de Valls, el padrón de 1378 recoge 542 vecinos (incluyendo aquellos exentos del pago de la talla o nichil). El libro de estimes no indica, salvo en algún caso puntual, 
referencias a los oficios de los contribuyentes, pero es presumible que una gran parte de ellos, si no su mayoría, fueran campesinos. En otras localidades de la Corona de Aragón, centros regionales de relevancia con poblaciones incluso mucho mayores, como Vilafranca del Cid, Sagunto o Castellón, que superaban con creces el millar de habitantes, más de la mitad de la población era de extracción campesina ${ }^{16}$. Es de esperar que esta fuera la situación de Valls, como, de hecho, lo era de otras poblaciones de la zona del Campo de Tarragona, como Reus o la Selva. Aún así, Valls gozaba de una diferenciación social más marcada en relación a las otras localidades por su papel como centro de producción de paños, era centro de feria y mercado e, incluso, acogía a algunas familias de caballeros (Morelló Baget, 2001, pp. 301-302).

La comparación de Valls con Sevilla y Palma es, pues, imperfecta, pero puede utilizarse de base para extraer algunas ideas sobre las diferencias entre campo y ciudad y, posteriormente, ponerse en relación con otros casos peninsulares. De hecho, la principal idea que podemos observar es que las desigualdades no eran extremadamente diferentes entre ciudad y campo. Los casos de Valls y Sevilla, prácticamente coetáneos, muestran cómo el decil superior de cada localidad acumulaba una proporción muy similar de la riqueza, entre el 43 y el $47 \%$. De hecho, esta similitud se repite si se va acotando la horquilla a los contribuyentes más adinerados: el $5 \%$ más rico acumulaba un tercio de la riqueza en cada caso. El caso de Palma es más distante en el tiempo, y muestra ya unos niveles de desigualdad muy superiores a Valls y Sevilla, ya que en la capital mallorquina el decil superior acumulaba algo más de la mitad de la riqueza (56\%), y el $5 \%$ más rico el $40 \%$. El coeficiente de Gini de Valls es de hecho ligeramente superior al de Sevilla $(0,66$ frente a 0,58$)$, mientras que el de Mallorca supera el $0,7^{17}$.

Tabla 6. Proporción de la riqueza acumulada entre el $5 \%$ y el $1 \%$ más rico

\begin{tabular}{|l|c|c|}
\hline & 5\% más rico & 1\% más rico \\
\hline Valls (1378) & 31,99 & 10,82 \\
\hline Sevilla $(1384)$ & 57,45 & 33,53 \\
\hline Sevilla $(1384)^{*}$ & 32,99 & 17,87 \\
\hline Mallorca $(1478)^{*}$ & 41,98 & 17,91 \\
\hline
\end{tabular}

Notas: Los deciles de Sevilla con * corresponden a la distribución de la riqueza en esta población excluyendo los contribuyentes del estamento nobiliario (véase el texto)

${ }^{16}$ Sobre las dinámicas de las poblaciones de estos centros véase Furió, 1986, p. 194; Guinot, 2007, pp. 95-134 y Royo Pérez, 2010, p. 194, nota 1.

17 Todas las referencias a Sevilla en este párrafo toma los valores que no incluyen a los caballeros. 
Con todas las precauciones que requiere un proyecto en curso, del cual nuestro trabajo representa una contribución inicial, el contraste de Valls con los otros casos sugiere matizar la imagen antagónica entre unas urbes de profundas desigualdades y un campo con un cariz más igualitario. Es cierto que en las poblaciones más grandes, con una vinculación comercial e industrial más elevada, existían grupos profesionales más especializados y estratos sociales que acumulaban cantidades de riqueza notables. Ahora bien, el medio rural no era un mundo homogéneo, donde una masa uniforme de labradores poseyera patrimonios similares. El caso de Valls, por ejemplo, presenta un coeficiente de Gini ligeramente superior al de otra localidad catalana, Cervera, este ya un núcleo con carácter más urbano $(0,52$ en 1369). Otros trabajos han mostrado cómo en comunidades esencialmente campesinas los coeficientes de Gini pueden rondar los que acabamos de ver. En el caso del reino de Valencia, de donde poseemos estudios locales gracias a los trabajos de Pau Viciano y Antoni Furió, sabemos que durante la década de los 1470 el coeficiente de Gini de una población como Alzira podía situarse en 0,51, muy similar al de su área rural circundante $(0,48)$ y al de la propia villa de Castellón $(0,44)$. El de Sueca puede establecerse en 0,52 hacia los $1490^{18}$.

Aunque es necesaria mucha investigación aún a este respecto, es más que probable que, como suele pasar en otros debates de la disciplina, la oposición entre poblaciones urbanas y rurales no fuera tan acentuada. Seguramente, ni el campo era tan uniforme, ni la ciudad tan desigual. Como se ha esforzado en explicar la escuela valenciana, el medio rural era un ámbito donde podía manifestarse una estratificación social considerable, con sectores campesinos con patrimonios muy desiguales (Aparisi, 2015, pp. 336-357; Garcia-Oliver, 2007, pp. 88-101; Furió, 1982). Además, no todas las personas que vivían «en el campo" vivían de la tierra, sino que también había notarios, clérigos, carniceros y artesanos locales semiespecializados. Por otra parte, las ciudades podían albergar todo tipo de sectores sociales, pero seguramente hay que atribuir buena parte de los altos coeficientes de Gini que estas arrojan a unas élites muy concretas de patrimonios extraordinariamente altos. Tómese por ejemplo el caso analizado de Sevilla, en el que, si se excluye al estamento nobiliario, el coeficiente de Gini baja de más de 0,8 a cerca de 0,6 .

Otro factor de análisis es la repercusión de la desigualdad social entre hombres y mujeres en la desigualdad económica. La forma en que la sociedad medieval estaba concebida y organizada determinaba y limitaba el papel que las mujeres podían llegar a realizar en la vida social, más allá de su potencialidad particular. Sin embargo, el análisis de estas fuentes fiscales nos muestra la presencia de mujeres en

18 Los coeficientes de Gini mencionados en este párrafo de Cervera, Castellón, Alzira y Sueca pueden encontrarse en Furió, 2015, pp. 16 y 19. Estos provienen a su vez de Ribalta y Turull, 1992; Furió, 1982 y Viciano, 1997. 
el mundo fiscal, siendo tasadas y apareciendo como cabezas de familia o negocios. Por ejemplo, en el caso de Sevilla vemos que de los 2.599 contribuyentes, 581 son mujeres, es decir, un $22,3 \%$ de los tasados.

En la mayoría de los casos, las mujeres que aparecen en estos registros son viudas, que se mencionan junto al nombre del difunto marido y la profesión de este. La viudedad conllevaba para muchas de ellas la necesidad, o la oportunidad, dependiendo de cómo se vea, de hacerse cargo de la familia y mantenerla a flote, especialmente si los hijos eran menores o jóvenes sin casar.

En las fuentes, las mujeres que aparecen no son solo viudas que han quedado a cargo a su familia, pues también aparecen un importante número de mujeres a las que se les atribuye una profesión propia. En el ámbito laboral, las mujeres de la Edad Media desarrollaban todo tipo de trabajos, remunerados o no, aunque, en muchas ocasiones, el trabajo femenino que ha quedado referenciado en las fuentes fiscales se relaciona con actividades domésticas que eran arrendadas a otras personas. La profesionalización de estas tareas conllevó la propagación en las fuentes de mujeres profesionales como las criadas, las lavanderas, las cocineras, etc. Además, más allá de oficios propios del ámbito doméstico, encontramos mujeres en todos los sectores profesionales y realizando todo tipo de actividades. Puede que no fueran maestras de oficios, pero en los registros como el de Sevilla, por ejemplo, aparecen mesoneras, pescaderas, lencera, correderas, médicos (físicas), gallineras, mieleras (encargadas de la venta de la miel), alfareras, torneras, segaderas, cordoneras, campesinas, especieras, candeleras, traperas, alcahuetas, panadera, entre otras.

Pero la desigualdad entre hombres y mujeres no era la única posible. La desigualdad entre la condición social de las mujeres también condicionaban la posición económica. Muchas mujeres de la nobleza y realeza no ocuparon ningún cargo en la administración ni ningún oficio, pero controlaban importantes cantidades de dinero, procedente de sus jurisdicciones, convirtiéndose en algunos casos en la cabeza de familias nobiliarias e, incluso, del trono. Estas mujeres tenían la autoridad propia de su condición social y una gran capacidad adquisitiva que las convierte no solo en élites sociales sino también económicas de su época.

Estas diferencias sociales y económicas entre las mujeres, se manifiestan en la distribución de riqueza por deciles y los coeficientes de Gini resultantes.

Tabla 7. Distribución de la riqueza por deciles entre las mujeres

\begin{tabular}{|l|c|c|c|c|c|c|c|c|c|c|}
\hline & D1 & D2 & D3 & D4 & D5 & D6 & D7 & D8 & D9 & D10 \\
\hline Valls (1378) & 0,44 & 0,95 & 1,54 & 1,81 & 2,44 & 3,62 & 5,92 & 9,74 & 19,96 & 53,53 \\
\hline Sevilla (1384) & 1,02 & 1,07 & 1,56 & 2,15 & 2,15 & 2,64 & 4,22 & 5,74 & 11,47 & 67,90 \\
\hline Mallorca (1478) & 1,48 & 2,21 & 2,07 & 2,07 & 2,68 & 3,37 & 4,15 & 5,67 & 10,43 & 65,91 \\
\hline
\end{tabular}


Gráfica 3. Distribución de la riqueza por deciles entre las mujeres

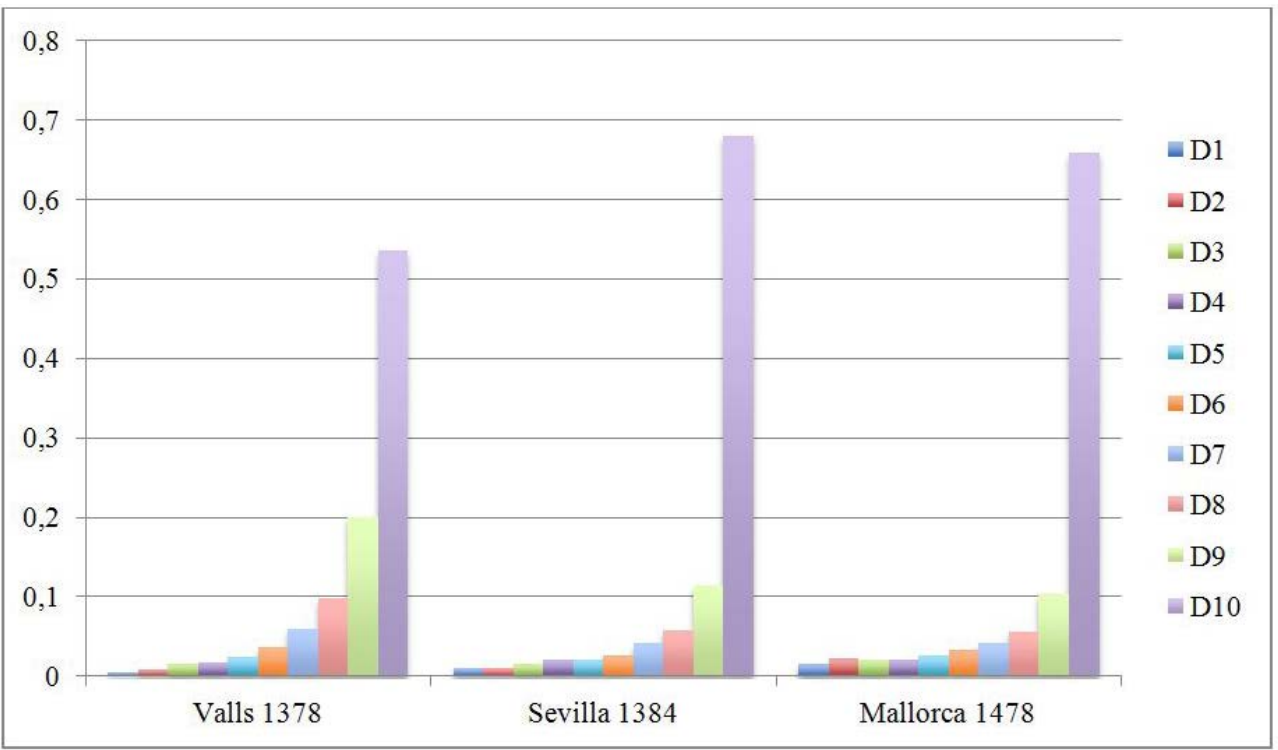

En general, la desigualdad entre los primeros nueve deciles en los cálculos generales, incluyendo hombres y mujeres, son prácticamente idénticos a los que solo computan a las mujeres registradas. Sin embargo, encontramos un incremento de los porcentajes de riqueza acumulada en el décimo decil, incrementándose casi un $6 \%$ en el caso de Valls y un $9 \%$ en el de Palma, siendo solo $0,36 \%$ más bajo en Sevilla.

Este aumento en la riqueza del décimo decil tiene su repercusión en las cifras del coeficiente de Gini calculado para las mujeres tasadas en estas tres localidades.

Tabla 8. Coeficientes de Gini de las mujeres en comparación a los generales

\begin{tabular}{|l|c|c|}
\hline & Gini (mujeres) & Gini (general) \\
\hline Valls (1378) & 0,73 & 0,66 \\
\hline Sevilla (1384) & 0,81 & 0,80 \\
\hline Mallorca (1478) & 0,78 & 0,72 \\
\hline
\end{tabular}

Como vemos, el coeficiente calculado para las mujeres en los tres casos es mayor que el calculado para el conjunto de la población fiscalizada, lo que va en relación con el auge del porcentaje de riqueza acumulado por la décima parte más rica. En Sevilla, este auge no es tan grande, puesto que en la fuente fiscal ya se registra la nobleza, en la que hay un gran número de mujeres, incluso algunas de linaje regio, como Isabel de la Cerda, quien contribuiría con 50.000 maravedís a la 
guerra contra Portugal. En los otros casos el auge de la desigualdad rondaría casi un $10 \%$.

Con todo, la aplicación del coeficiente Gini para los estudios de género muestra cómo la desigualdad económica es todavía mayor entre las mujeres, como consecuencia de la mayor acumulación de riqueza de la capa más boyante de estas, formada en su mayoría por mujeres de la nobleza o viudas enriquecidas. De este modo, se vislumbra una relación entre la desigualdad social y la desigualdad económica, provocando que esta última sea todavía mayor en los sectores desfavorecidos por la organización social vigente.

\section{CONCLUSIONES}

Aunque en un estado inicial, nuestro proyecto pretende contribuir a las grandes preguntas sobre las dinámicas de la desigualdad económica y su naturaleza en el período medieval. En este trabajo no se ha podido abordar una perspectiva cronológica, pero sí diversos análisis transversales para estudiar los rostros de la desigualdad, fuera entre sectores sociales, entre el medio urbano y el rural o por el género. Con ello, nuestra aproximación plantea, al menos, tres grandes puntos de interés.

Como era previsible, existían grandes diferencias entre grupos sociales, especialmente aquellos más dedicados al sector artesanal y profesiones urbanas, como los notarios o los mercaderes. Ahora bien, nuestro análisis muestra que también había diferencias dentro de ellos, muy acentuadas en el caso de sectores que normalmente consideraríamos como miembros del patriciado urbano (como los mercaderes). Estudiar la estratificación interna dentro de cada sector social nos obliga a redefinir qué es pertenecer a un sector social particular, lo cual otorga a este aspecto una importancia fundamental. Lo mismo ocurre con el caso del análisis interparroquial, que evidencia que existían concentraciones de grupos determinados en áreas de la ciudad. Ahora bien, no hay que tomar estas "concentraciones» como «especializaciones» espaciales. Las altas variaciones en el coeficiente de Gini evidencian que grupos sociales muy variados, tanto en riqueza como en actividad socioprofesional, coexistían en los mismos espacios urbanos.

La perspectiva que ofrece la desigualdad en las relaciones campo-ciudad también lleva a matizar muchas ideas tradicionales. Los casos estudiados, en comparación con material ya publicado, sugieren que el medio rural no era un «espacio de igualdad». De la misma manera que la ciudad no era un ámbito de desigualdades absolutas, sino que era matizable de ciudad en ciudad y, a su vez, entre sus diferentes barrios y parroquias, en el campo podían existir desigualdades altas o incluso similares a las de algunas ciudades. Esto se debería no solo a la 
existencia de grupos particulares no vinculados directamente con el sector agrario, que acumulaban riqueza de actividades no agrícolas, sino también a que había grupos más enriquecidos dentro del propio campesinado.

Finalmente, posiblemente sea el estudio de las desigualdades económicas en el género uno de los aspectos más olvidados, y que reviste de una novedad mayor. Hasta la fecha, los estudios de género no han cuantificado cómo los niveles de desigualdad económica eran mayores entre las mujeres, producto de la desigualdad que estas sufrían en la organización social. Estas conclusiones, aunque son resultado del análisis de fuentes fiscales medievales, también son sumamente actuales cuando la desigualdad económica se ha acrecentado y ha supuesto que muchas mujeres hayan visto sus opciones de acceder al mercado laboral mermadas o imposibilitadas, provocando una fuerte brecha salarial o, incluso, la dependencia económica y, a su vez, dificultando el laborioso camino hacia la igualdad de género y de derechos.

Todos estos aspectos revisten de un interés transversal para entender la lógica de la desigualdad. El estudio del índice de Gini y de la distribución de la riqueza por deciles, en sí mismo, permite mirar a la sociedad medieval cara a cara. Se trata de una apuesta por la renuncia a las clasificaciones tradicionales de la disciplina, que llaman a extrapolaciones imprecisas sobre qué es ser rico o qué es ser pobre (como las que surgen al hablar de "noble» y "artesano», "ciudad» y «campo»). Es el estudio de las fuentes fiscales el que nos permite relativizar todas estas etiquetas en favor de concebir la sociedad medieval en sectores clasificados por criterios materiales y patrimoniales. Ahora bien, nuestra aproximación no es suficiente para poder contribuir al debate sobre la dinámica de la desigualdad en el período bajomedieval. Necesitamos continuar volcando las fuentes en bases de datos para abordar una perspectiva cronológica, que permita estudiar tendencias en el medio y largo plazo y su comparación con otros casos peninsulares y europeos.

\section{BIBLIOGRAFÍA}

Alfani, G. (2009). Prima della curva di Kuznets: stabilità e mutamento nella concentrazione di ricchezza e proprietà in età moderna. En Alfani, G. y Barbot, M. (eds.), Ricchezza,valore, proprietà in Età Preindustriale. 1400-1850 (pp. 143-168). Venecia: Marsilio.

Alfani, G. (2010). Wealth inequalities and population dynamics in northern Italy during the early modern period. Journal of interdisciplinary history, 40(4), 513549. 
Alfani, G. (2014). Economic inequality in northwestern Italy: A long-term view (fourteenth to eighteenth centuries). Università Bocconi, Dondena working paper (inédito).

Alfani, G. y Di Tullio, M. (2014). Economic inequality, population and environment in Early Modern Italy: the case of the Republic of Venice, 16th-18th centuries. Università Bocconi, Dondena working paper (inédito).

Alfani, G. y Frigeni, R. (2016). Inequality (un)perceived. The emergence of a discourse on economic inequality from the Middle Ages to the Age of Revolutions. Journal of European economic history, 45(1), 21-66.

Álvarez, M., Ariza, M., Mendoza, J. y Collantes de Terán, A. (2001). Un padrón de Sevilla del siglo XIV. Estudio filológico y edición. Sevilla: Ayuntamiento de Sevilla.

Ammannati, F., De Franco, D. y Di Tullio, M. (2014). Misurare la diseguaglianza economica nell'età preindustriale: un confronto fra realtà dell'Italia centrosettentrionale. Università Bocconi, Dondena working paper (inédito).

Aparisi, F. (2015). Village entrepreneurs. The economic foundations of Valencian rural elites in the fifteenth century. Agricultural History, 89(3), 336-357.

Atkinson, A. B., Piketty, T. y Saez, T. (2011). Top Incomes in the Long Run of History. Journal of economic literature, 49(1), 3-71.

Barceló, M. (1985). La ciudad de Mallorca en el último cuarto el siglo XV: parroquias y red viaria. En la España medieval, 7, 1321-1332.

Bekar, C. y C. Reed. (2013). Land markets and inequality: evidence from medieval England. European review of economic history, 17(3), 294-317.

Broadberry et al. (2015). British economic growth, 1270-1870. Cambridge: Cambridge University Press.

Furió, A. (1982). Camperols del País Valencià. Sueca, una comunitat rural a la tardor de l'Edat Mitjana. Valencia: Institució Alfons el Magnànim.

Furió, A. (2015). Economic Inequality in Iberia before and after the Black Death: Valencia in the fourteenth century. XVII World Economic History Congress, Kyoto, working paper, (inédito). 
Furió, A. (2017). Avant le cadastre. Les livres d'estimes du royaume de Valence au bas Moyen Âge. En J.-L. Abbé, F. Hautefeuille y J. Le Pottier (eds.), Estimes, compoix et cadastres de l'Europe médiévale et moderne (Agde / Montpellier, 25 et 26 septembre 2015), en prensa.

García Marsilla, J. V. (1996). La génesis de la fiscalidad municipal en la ciudad de Valencia (1238-1366). Revista d'Història Medieval, 7, 149-172.

Garcia-Oliver, F. (2007). Viure a l’Edat Mitjana. La família rural. Canelobre, 52, 88101.

Göran, T. (2015). La desigualdad mata. Madrid: Alianza.

Guinot Rodríguez, E. (2007). Morvedre. Història d'una vila valenciana medieval, Braçal, 35-36, 95-134.

Hanus, J. (2013). Real inequality in the early modern Low Countries: the city of 'sHertogenbosch, 1500-1660. Economic history review, 66, 733-756.

Hanus, J. (2014). Affluence and inequality in the Low Countries. The city of 's-Hertogenbosch in the long sixteenth century, 1500-1650. Lovaina: Peeters Publishers.

Hatcher, J. (2011). Unreal wages. Long-run living standards and the 'Golden Age' of the fifteenth century. En B. Dodds y C. Liddy (eds.), Commercial activity, markets and entrepreneurs in the Middle Ages: essays in honour of Richard Britnell (pp. 1-24), Woodbridge: The Boydell Press.

Kuznets, S. (1955). Economic growth and income inequality. American economic review, 45, 1-28.

Milanovic, B., Lindert, P. y Williamson, J. (2007). Measuring Ancient Inequality, NBER working papers (inédito).

Milanovic, B., Lindert, P. y Williamson, J. (2011). Pre-Industrial Inequality. The economic journal, 121, 255-272.

Morelló Baget, J. (2003). Les estimes de Valls de 1378: repartició de la riquesa i sistema contributiu. Historia et documenta, 7, pp. 9-74 (esp. 37-74). 
Morelló Baget, J. (2001). Fiscalitat i deute públic en dues viles del camp de Tarragona. Reus i Valls, segles XIV-XV. Barcelona: Consejo Superior de Investigaciones Científicas.

Modalsli, J. H. (2011). Inequality and growth in the very long run: inferring inequality from data on social groups. Universidad de Oslo, working paper (inédito). Recuperado el 02 del 05 del 2017, en https://www.sv.uio.no/econ/english/ research/unpublished-works/working-papers/pdf-files/2011/Memo-11-2011. pdf

Morrison, C. (2000). Historical perspectives on income distribution: the case of Europe. En A. Atkinson y F. Bourguignon (eds.), Handbook of income distribution (pp. 217-260). Amsterdam: Elsevier.

Oliva Herrer, H. R. (2000a), Sobre los niveles de vida en Tierra de Campos a fines del medievo. Edad Media: revista de historia, 3, 175-226.

Oliva Herrer, H. R. (2000b), Propiedad, explotación agraria y organización del trabajo en Tierra de Campos a fines de la Edad Media. Historia agraria, 21, 33-61.

Piketty, T. (2014). El capital en el siglo XXI. Madrid: Fondo de cultura económica.

Piketty, T., Postel-Vinay, G. y Rosenthal, J.-L. (2006). Wealth concentration in a developing economy: Paris and France, 1807-1994. The American Economic Review, 96(1), 236-256.

Reis, J. y Martins, C. A. (2012). Inequality in early modern Europe. The «strange» case of Portugal, 1550-1770. Universidad Carlos III de Madrid, conferencia "Wellbeing and inequality in the long run», working paper (inédito).

Ribalta, J. y Turull, M. (1992). Ciutat i poder en el feudalisme declinant a la Catalunya baixmedieval. Diferenciació social i distribució social de l'espai urbà a Cervera, 1340-1382. Anuario de estudios medievales, 22, 79-164.

Royo Pérez, V. (2010). Las industrias rurales en Vilafranca al final de la Edad Media. En C. Villanueva Morte; D. Reinaldos Miñarro, J. Maíz Chacón e I. Calderón Medina (eds.), Nuevas investigaciones de jóvenes medievalistas (pp. 193-208). Murcia.

Rubin, M. (1987). Charity and community in medieval Cambridge. Cambridge: Cambridge University Press. 
Ryckbosch, W. (2012). A Consumer Revolution under Strain. Consumption, Wealth and Status in Eighteenth-Century Aalst (Southern Netherlands). Tesis doctoral inédita, Universidad de Amberes y Universidad de Gante.

Ryckbosch, W. (2014). Economic inequality and growth before the industrial revolution: a case study of the Low Countries (14th-19th Centuries). Università Bocconi, Dondena working paper n. 67 (inédito). Recuperado el 02 del 05 de 2017, en ftp://ftp.dondena.unibocconi.it/WorkingPapers/Dondena_WP067. pdf

Santiago-Caballero, C. (2011). Income inequality in central Spain, 1690-1800, explorations in economic history, 48(1), 83-96.

Scheidel, W. (2016). The great leveler. Violence and the history of inequality from the stone age to the twenty-first century. Princeton, NJ: Princeton University Press.

Slivinski, A. ySussman, N. (2009). Taxation Mechanisms and Growth in Medieval Paris. European Economic History Association Conference, working paper (inédito). Recuperado el 02 del 05 de 2017, en http://www.parisschoolofeconomics.eu/ docs/ydepot/semin/texte0910/SUS2010TAX.pdf

Soltow, L. y Van Zanden, J. L. (1998). Income and wealth inequality in the Netherlands, 16th-20th century. Amsterdam: Transaction Publishers.

Sussman, N. (2006). Income Inequality in Paris in the heyday of the commercial eevolution. Conference for the Canadian Network of Economic Historians, Vancouver, Canada. Woking paper (inédito).

Tello, E. (1987). Pagesos, menestrals i rendistes. Cervera i la Segarra en l'arrencada industrial catalana. Universitat de Barcelona, tesis doctoral inédita.

Van Zanden, J. L. (1995). Tracing the beginning of the Kuznets curve: Western Europe during the early modern period. Economic history review, 48(4), 643-664.

Viciano, P. (1997). Poder municipal i grup dirigent local al País Valencià: la vila de Castelló de la Plana (1375-1500). Valencia: PUV.

Wilkinson, R. (2016). Desigualtats, benestar i democracia. Eines per a l'esquerra nacional, 27, 117-143. 